\title{
Determinación del perfil de ácidos grasos de bacterias del género Vibrio por cromatografía de gases
}

\author{
Rodrigo Valenzuela Fernández, René Cortez Silva, \\ Miguel Zazopulos Garay, Jaime Carmi Karmy* \\ Laboratorio de Cromatografía, Departamento de Química, Universidad Técnica Federico Santa María - UTFSM, \\ Sede Viña del Mar, Avenida Santa María 6090, casilla 920, Viña del Mar, Chile \\ e-mail: jaime.carmi@usm.cl
}

\section{Resumen}

El género Vibrio comprende varias especies de importancia clínica, muchas de ellas relacionadas con enfermedades transmitidas por los alimentos. Es conveniente contar con técnicas alternativas que apoyen la identificación de especies de géneros bacterianos como Vibrio. Se puede utilizar la cromatografía gas líquido para determinar el perfil de los ésteres metílicos de los ácidos grasos presentes en la estructura celular de los microorganismos. El objetivo del presente trabajo es determinar y cuantificar el perfil de ésteres metílicos de los ácidos grasos presentes en Vibrio vulnificus, Vibrio parahaemolyticus, Vibrio cholerae y Vibrio alginolyticus, además de otras especies como Escherichia coli y Staphylococcus aureus, con el fin de determinar los ácidos grasos más relevantes presentes en los microorganismos, así como también posibles relaciones entre ellos. Para esta identificación, cada cepa de Vibrio se hace crecer en caldo soya tripticasa (TSB) con 1\% de cloruro de sodio, después de la incubación se centrifuga el cultivo para separar la masa microbiana del caldo. La masa bacteriana obtenida se somete a una lisis con ondas de alta frecuencia, se le agrega una solución de hidróxido de potasio 0,5 Normal en metanol, se extrae el insaponificable, el residuo se acidifica y los ácidos grasos se extraen y metilan, inyectándose a un cromatógrafo equipado con una columna BPX-70 de 0,22 mm de diámetro y detector de ionización por llama, FID. Los resultados indican que el perfil de ácidos grasos es único para cada especie analizada y significativamente diferente, tanto para cada especie de Vibrio como para las otras bacterias consideradas. Se destacan, como indicadores de diferenciación a los ácidos grasos mirístico, palmítico, cis-oleico, trans-oleico, cis-linoleico y araquídico. También la relación $\omega-9 / \omega-6$ es significativamente distinta para cada especie ensayada. En consecuencia, el perfil de ácidos grasos puede ser una prueba alternativa para la identificación del género Vibrio a un bajo costo y tiempo relativos.

Palabras clave

Ácidos grasos; Vibrio; cromatografía gas-líquido; bacteria.

\section{Determination of fatty acid of Vibrio bacteria by gas chromatography}

\section{Abstract}

The genus Vibrio includes several species of clinical importance, many of them related to foodborne diseases. It is desirable to have alternative techniques to support the identification of bacterial genera and 
species of Vibrio. Capillary gas Chromatography can be used to determine GLC profile for the methyl esters of the fatty acids present in the cellular structure of the microorganisms. The objective of this study is to determine and quantify the profile of methyl esters of fatty acids present in Vibrio vulnificus, Vibrio parahaemolyticus, Vibrio cholerae and Vibrio alginolyticus, and other species such as Escherichia coli and Staphylococcus aureus, in order to determine the fatty most relevant acids present in microorganisms, as well as any relationship between them. For this identification, each Vibrio strain is grown in trypticase soy broth (TSB) with $1 \%$ sodium chloride, after incubation the culture is centrifuged to separate the broth microbial mass. The bacterial mass obtained was subjected to an breakage with high-frequency waves, a 0.5 Normal potassium hydroxide solution in metanol is added, the unsaponifiable is extracted, the residue was acidified and the fatty acids were extracted and methylated, injecting in a chromatograph equipped with a BPX-70 column of $0.22 \mathrm{~mm}$ diameter and flame ionization detector, FID. The results indicate that the fatty acid profile is unique to each species analyzed and therefore significantly different for each species of Vibrio bacteria and for other consideration. Stand as indicators of differentiation fatty acids myristic, palmitic, oleic cis-, trans-oleic acid, cis-linoleic and arachidonic. $\omega-9 / \omega-6$ relationship is also significantly different for each species tested. Consequently, the fatty acid profile may be an alternative test for the identification of Vibrio at low cost and relative time.

Keywords

Fatty acids; Vibrio; gas liquid chromatography; bacteria.

\section{Antecedentes generales}

\section{El Manual de Bergey define a Vibrio como}

[...] pequeño, recto, ligeramente curvo, curvado, o una coma en forma de barras, con un tamaño variable entre $0,5-0,8 \mu \mathrm{m}$ de ancho y $1,4-2,6 \mu \mathrm{m}$ de largo [...] (p. 494) ${ }^{[1]}$.

Es una bacteria gram negativa que no forma endoesporas, presenta movilidad debido a uno o más flagelos polares que se encuentra adjunto a una cápsula continua junto con la membrana externa de la pared celular. En medio de cultivo sólido pueden llegar a desarrollar numerosos flagelos laterales la que se mueven con una longitud de onda menor que el flagelo polar principal. Son bacterias anaerobias facultativas, o sea que son capaces de utilizar metabolismo respiratorio $y$ fermentativo a la vez ${ }^{[1,3,4,8,9,14]}$.

Existen 12 especies patógenas, de las cuales se ha demostrado que 8 de ellas están relacionadas directamente con los alimentos ${ }^{[4]}$. La mayoría de las especies crecen bien en medios que contengan agua de mar, a su vez existen distintos tipos de enriquecimiento asociados al agar TCBS, de los cuales las especies de interés parti- cular para este trabajo pueden ser divididos en sacarosa-positivos (quiere decir que fermenta la sacarosa): V. cholerae y $V$. alginolyticus y sacarosa-negativos: V. parahaemolyticus y $V$. vulnificus ${ }^{[1,4]}$.

Uno de los objetivos primordiales de este estudio es desarrollar una técnica que sirva para apoyar una identificación de bacterias a nivel de especie, con la ventaja de ser rápida y versátil. Cabe destacar que el tipo de fase estacionaria utilizada en la separación cromatográfica es capaz de discriminar ácidos grasos insaturados en isómeros cis- y trans-.

Las especies microbianas del género Vibrio son bacterias propias del agua y especialmente de ambientes marinos. La mezcla de agua marina con agua dulce y en la cual las condiciones de salinidad, temperatura o movimiento del agua, entre otros factores, son más homogéneas, pueden incluso ser los microorganismos predominantes. Su alta presencia determina que los alimentos más frecuentemente contaminados sean los productos de la pesca. El género Vibrio comprende varias especies de importancia sani- 
taria, relacionadas muchas de ellas con enfermedades gastrointestinales y en particular por enfermedades transmitidas por los alimentos de origen marino, principalmente moluscos bival$\operatorname{vos}^{[2,12,13,14]}$.

\section{1 Ácidos grasos bacterianos}

El metabolismo de ácidos grasos es un componente fundamental del metabolismo celular $^{[1,14]}$. Los ácidos grasos son esenciales en la elaboración de bloques de fosfolípidos de la membrana. La necesidad para precisar la estructura de ácidos grasos es importante para entender aspectos relacionados con la biosíntesis y para incrementar su taxonomía ${ }^{[5,6,7,10]}$.

Para la determinación de ácidos grasos bacterianos por cromatografía de gases hay que tener en consideración ciertos aspectos. En primer lugar, si se quiere realizar un análisis cuantitativo de los ácidos grasos hay que tener en cuenta el medio que se utilizó para su crecimiento, porque puede inducir a errores por los ácidos grasos que el medio contiene ${ }^{[7,10]}$.

Existen ciertos factores puntuales que influencian el contenido de ácidos grasos y son acetato, glicerol, carbohidratos, lípidos y sustancias nitrogenadas presentes en el medio, oxígeno suplementario, $\mathrm{pH}$ y tiempo del cultivo ${ }^{[10]}$.

Los ácidos grasos, entre 9 y 20 átomos de carbono, de acuerdo a su naturaleza química, pueden ser empleados como un criterio de clasificación en bacterias, especialmente en las gram negativas no fermentadoras. Con el gran avance que ha tenido la cromatografía gaseosa, se ha podido lograr una buena resolución de estos ácidos grasos, incluyendo los hidroxiácidos, y se ha convertido en una herramienta práctica para un amplio rango de bacterias ${ }^{[10]}$.

Se han detectado cadenas de ácidos grasos menores a 10 átomos de carbono, pero en muy pequeñas cantidades; por otro lado los ácidos grasos con más de 10 átomos de carbono constituyen una proporción mayor del contenido total de ácidos grasos, los que incluyen ácidos grasos pesados (24:0, lignocérico y 28:0, octacosanoico). Las cadenas ramificadas predominan en bacterias gram positivas, y no se ha reportado ácidos grasos de cadena recta mayores a C28 excepto en el género Mycobacteria ${ }^{[10,11]}$.

El ácido graso que se encuentra con mayor frecuencia es el palmítico que tiene 16 átomos de carbono. Le siguen, respectivamente: esteárico (18:0), mirístico (14:0) y láurico (12:0). En la bacteria Escherichia coli se pueden encontrar distintos tipos de ácidos grasos, entre los que se incluyen 2 hidroxiácidos: ácido $\beta$-hidroximirístico y $\beta$-hidroxidecanoico ${ }^{[10]}$.

En especies de Vibrio yen E. coli, la mayor cantidad de ácidos grasos son el ácido hexadecanoico y octadecenoico. Todas las especies de Vibrio se pueden diferenciar fácilmente de $E$. coli, porque el contenido del ácido hexadecenoico es mayor que la del ácido hexadecanoico, lo que en E. coli ocurre al revés. Siete de diez especies de Vibrio, que incluyen el $V$. parahaemolyticus, $V$. cholerae, V.alginolyticus, V.vulnificus, V.fluvialis, V. harveyi y $V$. splendidus contienen los ácidos cis-9-hexadecenoico y cis-11-hexadecenoico, mientras que $V$. metschnikovii, $V$. anguillarum y $V$. gazogenes no presentan el acido cis-11-hexadecenoico, lo que permite una primera separación de especies $^{[7]}$.

\section{Parte experimental}

\subsection{Equipos}

- Cromatógrafo de gas Agilent Technologies, modelo 7890-A equipado con detector FID y software Integrador GC ChemStation Rev. B.03.02[341];

- Balanza semianalítica Sartorius modelo TE313S; 
- Baño de agua de ultrasonido UltraSONIC modelo $104 \mathrm{H}$;

- Baño de agua Memmert modelo DIN 128677-K1;

- Centrífuga SLW modelo Ultra-8V.

\subsection{Materiales}

- Columna SGE BPX-70 (70\% dicianopropil $30 \%$ dimetil polisiliconafenilsiloxano) $25 \mathrm{~m}$, ID $0.22 \mathrm{~mm}$, espesor de fase estacionaria: $0,25 \mu \mathrm{m}$;

- Helio extra puro grado 4,5 AGA;

- Hidrógeno extra puro grado 4,5 Indura.

- Aire Indura extra puro;

- Nitrógeno AGA. 99,995\%;

- Material usual de vidrio de laboratorio.

\subsection{Reactivos y soluciones}

- Estándar de ácidos grasos FAME mix rapseed, $100 \mathrm{mg}$ netos artículo $\mathrm{n}^{\circ}$ 07756-1 AMP Supelco;

- Hexano Merck p.a. para cromatografía.

\subsection{Cepas bacterianas utilizadas}

- Vibrio alginolyticus ATCC 33840;

- Vibrio cholerae ATCC 39318;

- Vibrio parahaemolyticus ATCC 17802;

- Vibrio vulnificus ATCC 43382;

- Escherichia coli ATCC 25922;

- Staphilococcus aureus ATCC 25923.

\subsection{Condiciones cromatográficas}

- Temperatura inicial: $150{ }^{\circ} \mathrm{C}$;

- Tiempo inicial: 2 minutos;

- Rampa: $5{ }^{\circ} \mathrm{C} / \mathrm{min}$;

- Temperatura final: $210^{\circ} \mathrm{C}$;

- Tiempo final: 10 minutos;

- Temperatura del inyector $220^{\circ} \mathrm{C}$;

- Temperatura del detector: $230^{\circ} \mathrm{C}$;
- Presión del gas transportador: 15 psi;

- Razón de Split: 50:1.

\subsection{Procedimiento}

- Crecimiento de cepas: las cepas, previamente aisladas, se hacen crecer en caldo TSB con $1 \%$ de $\mathrm{NaCl}$ a $25^{\circ} \mathrm{C}$ durante 24 horas;

- Preparación de esteres metílicos de ácidos grasos: Reunir entre 0,5 y $1 \mathrm{~g}$ de masa bacteriana libre de caldo, a la que se le adicionan $5 \mathrm{~mL}$ de agua destilada. Se introduce en baño ultrasonido con temperatura, centrifuga y se elimina el agua. Saponificar con $4 \mathrm{~mL}$ de una solución de $\mathrm{KOH}$ en metanol $0,5 \mathrm{M}$ durante 30 minutos a $80{ }^{\circ} \mathrm{C}$ en un baño de agua. Extraer con hexano el material insaponificable y descartarlo. Al residuo, adicionar $\mathrm{H}_{2} \mathrm{SO}_{4}$ al $15 \%$ hasta obtener un $\mathrm{pH}$ 2. Extraer los ácidos grasos con hexano y evaporar el solvente. Esterificar con una mezcla de $\mathrm{HCl}$-metanol $1 \mathrm{~N}$ a $80{ }^{\circ} \mathrm{C}$ en un baño de agua por 30 minutos. Extraer los esteres metílicos con hexano. Lavar el residuo con buffer fosfato $0,3 \mathrm{M}, \mathrm{pH} 12$ (se pesan 4,257 $\mathrm{g}$ de $\mathrm{Na}_{2} \mathrm{HPO}_{4}$ y $1,2 \mathrm{~g}$ de $\mathrm{NaOH}$ en un vaso de precipitado, se disuelven con poca cantidad de agua y se diluye a $100 \mathrm{~mL}$ con agua destilada), extraer con hexano y evaporar el solvente hasta tener un volumen de $1 \mathrm{~mL}$ aproximadamente e inyectar al cromatógrafo $1 \mu \mathrm{L}$ de muestra.

\subsection{Expresión de resultados}

Se utilizó el método de cuantificación por normalización de áreas, inhibiendo la integración del solvente a tiempo de retención desde 0,00 hasta 1,60 minutos.

\section{Resultados}

La identificación bacteriana por cromatografía de gases es un método recomendado por la APHA (American Public Health Association) ${ }^{[3]}$, la cual explica que es una técnica rápida para la 
identificación de bacterias pero el inconveniente es que no explica detalladamente una metodología a seguir para una reproducción de lo expuesto.

La mayor ventaja de este método es que a partir del perfil de ácidos grasos permite identificar microorganismos tanto a nivel intraespecie como interespecie, además permite analizar un amplio rango de muestras distintas ya que utiliza el mismo procedimiento. Este método es rápido, porque la muestra ambiental o de alimento previamente tratada según procedimientos microbiológicos, puede ser sembrada en agar TCBS y después del período de incubación, se toma una colonia y se siembra directamente en caldo TSB, con contenido variable de cloruro de sodio, de acuerdo a la especie que se quiera investigar.

El trabajo aquí presentado es importante también porque ayuda a ampliar el campo de tipificación de las bacterias, ya que los ácidos grasos pueden servir como indicadores de diferenciación entre especies bacterianas (Figura 1), conociendo el contenido de los ácidos grasos mayoritarios, principalmente. Se logra determinar los ácidos grasos por cromatografía de gases por el método de normalización de área donde el porcentaje de área de cada pico representa el porcentaje en peso del ácido graso; por lo cual este tipo de análisis puede ser una prueba alternativa y eficaz para la identificación microbiana.

Para que el método sea válido, se trató cada muestra de bacterias en triplicado, y cada extracto en hexano se inyectó en triplicado, mostrándose los valores promedio con la desviación estándar calculada a nivel de método, no de la réplica de inyección.

De la Tabla 1 y Figura 2 se puede observar que para $V$. cholerae, de mayor a menor porcentaje de área, los ácidos mayoritarios para la identificación respectiva son: palmítico con $22,81 \%$, esteárico con $18,30 \%$, araquídico con
8,74\%, cis-oleico con 5.07\% y láurico con 5,04\%, mientras que para $V$. parahaemolyticus los ácidos mayoritarios son: palmítico con 21,23\%, esteárico con $15,38 \%$, láurico con $6,47 \%$, trans-oleico con 5,00\%, y cis-linoleico con 5,27\%, respectivamente, por lo que claramente se pueden asociar como distintos los ácidos que se repiten en ambos, palmítico, esteárico y láurico, aparte de existir una diferencia significativa en el \% en peso para cada ácido graso, además las desviaciones estándar del promedio de cada uno de ellos es pequeña, por ende se comprueba que el contenido de ácido graso es un criterio de identidad.

Cuando se compara $V$. cholerae con V. vulnificus, se repiten, para el último, los ácidos esteárico con $18,12 \%$, palmítico con $10,70 \%$, araquídico con $6,45 \%$ y láurico con $2,76 \%$, y nuevamente al presentar un menor $\%$ en peso para el ácido palmítico los porcentajes de área, pueden ser usados para la identificación respectiva. El $V$. alginolyticus tiene en común con $V$. cholerae los ácidos palmítico con $13,56 \%$, esteárico con $13,21 \%$, araquídico con $5,42 \%$ y láurico con $2,67 \%$, respectivamente y por el $\%$ en peso de los ácidos de mayor importancia pueden ser considerados como diferentes porque se aprecia que en $V$. vulnificus el contenido es menor, y por lo tanto tienen distinta identidad. V. vulnificus comparte con V.parahaemolyticus los ácidos esteárico, palmítico, araquídico y láurico; y por el orden \% en peso mayor de estos, sobretodo de los dos primeros ya que en $V$. parahaemolyticus el \% mayor es el palmítico, pueden ser identificados separadamente. Por otra parte, V. alginolyticus se relaciona con V. parahaemolyticus con los ácidos palmítico, esteárico y láurico; en este caso el orden de mayor a menor de estos tres es el mismo, pero el factor diferencial a nivel de especie para la identificación, es el porcentaje individual de los ácidos en el cual siempre tiene un mayor porcentaje el $V$. parahaemolyticus, pero para una mejor iden- 
FID1 A, Front Signal (FAME VIBRIO \ACEITE000175.D)

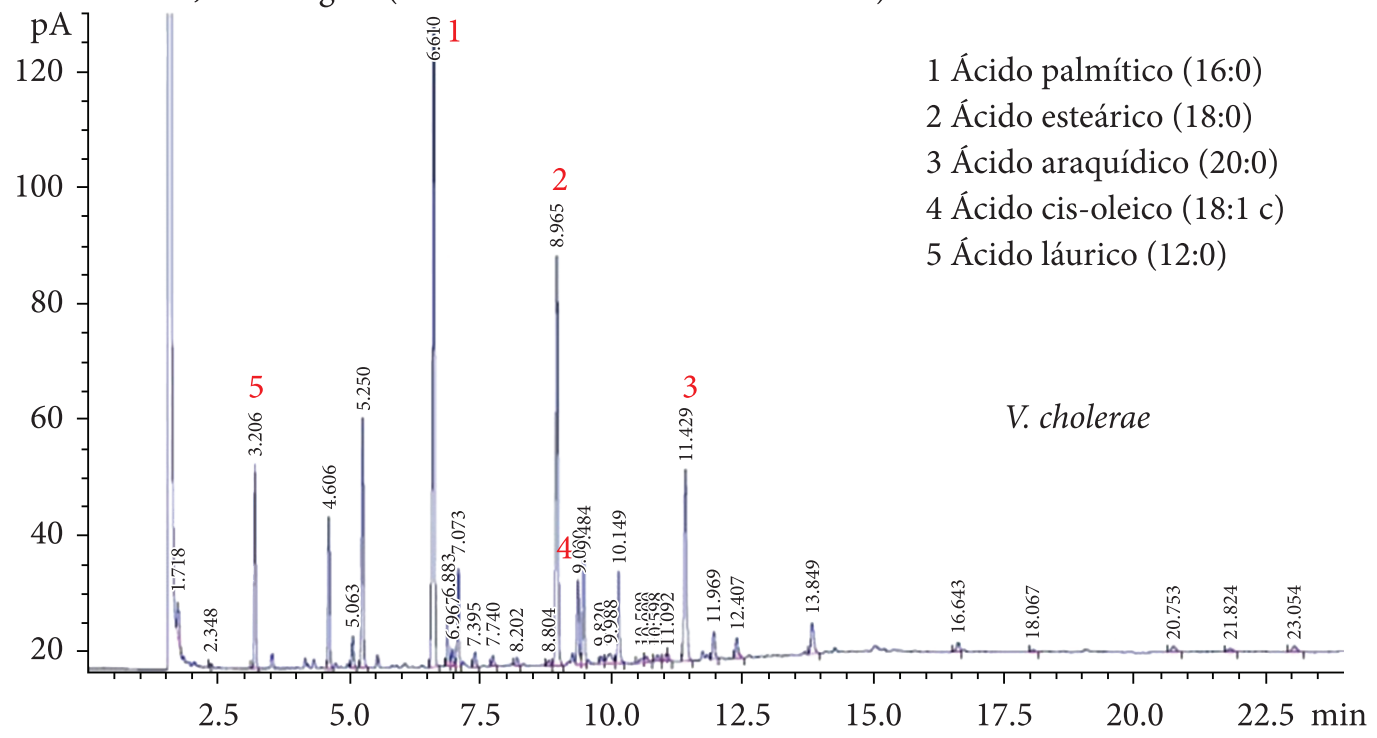

FID1 A, Front Signal (FAME VIBRIO $\backslash$ ACEITE000163.D)

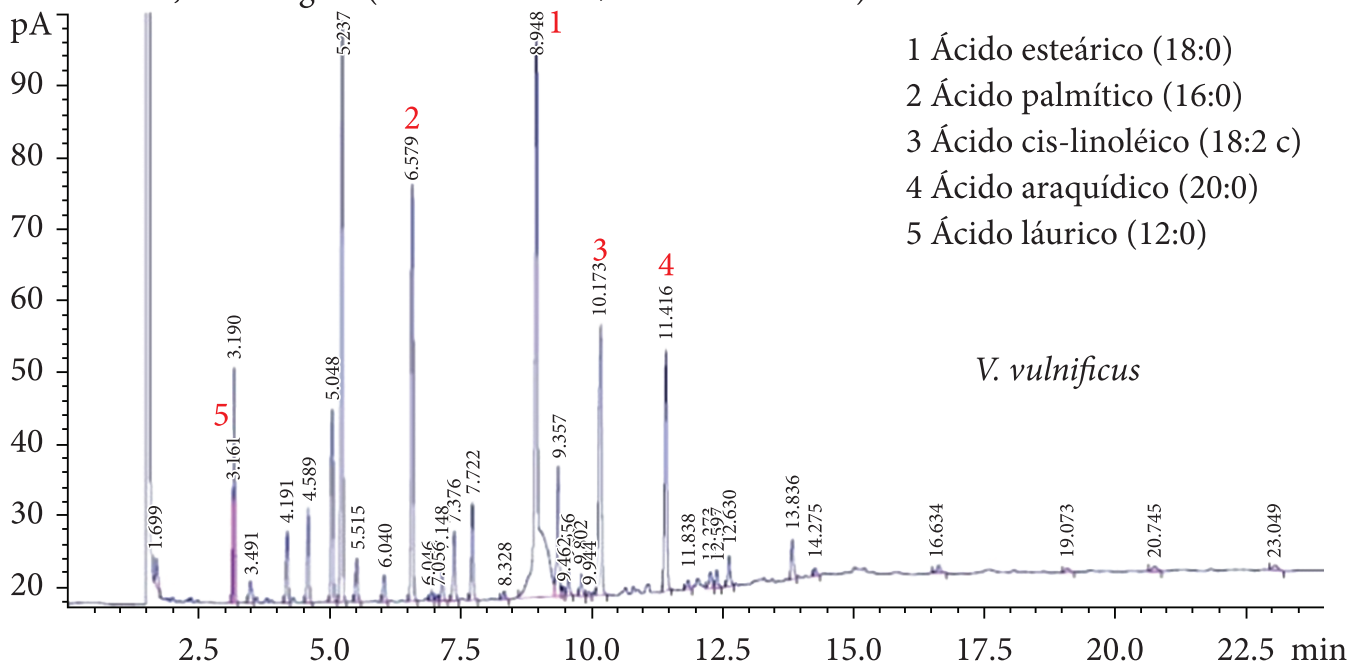

FID1 A, Front Signal (FAME VIBRIO \ACEITE000153.D)

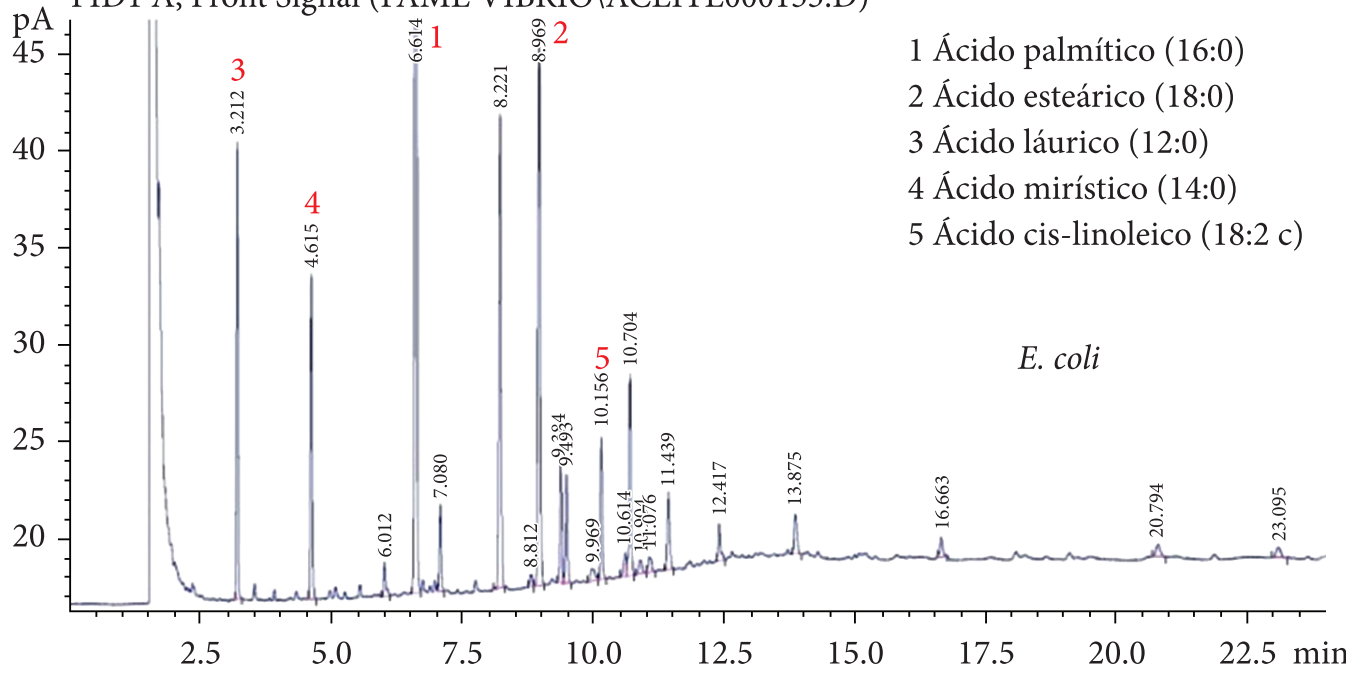

Figura 1 Cromatogramas de metilésteres de ácidos grasos producidos por distintas cepas bacterianas. 
FID1 A, Front Signal (FAME VIBRIO\ACEITE000167.D)

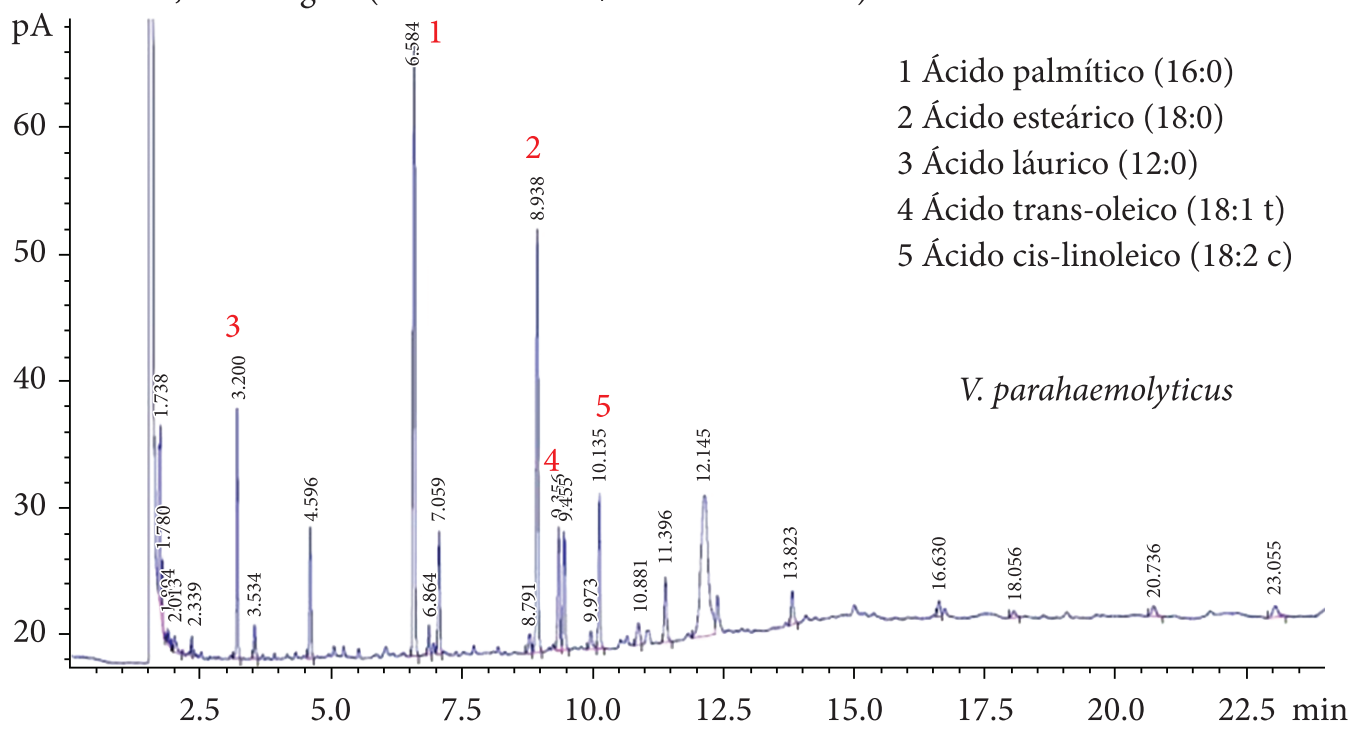

pA FID1 A, Front Signal (FAME VIBRIO \ACEITE000157.D)

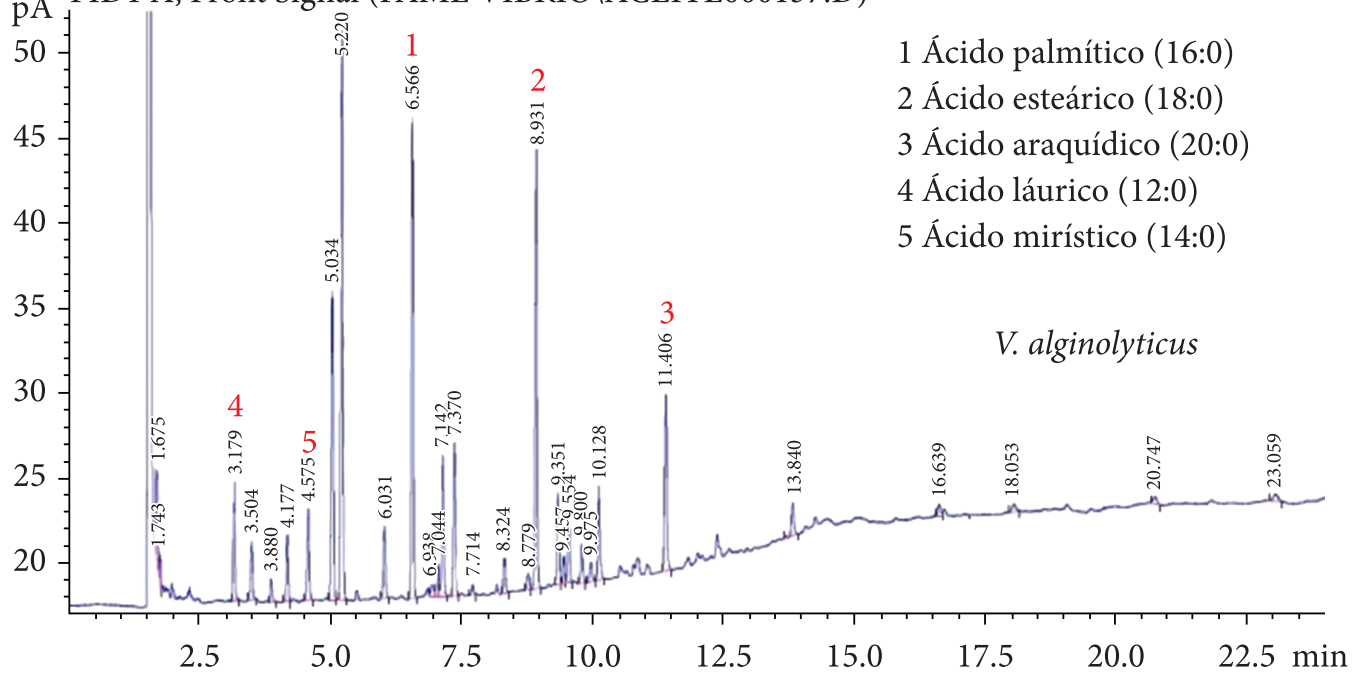

pA FID1 A, Front Signal (FAME VIBRIO $\backslash$ ACEITE000178.D)

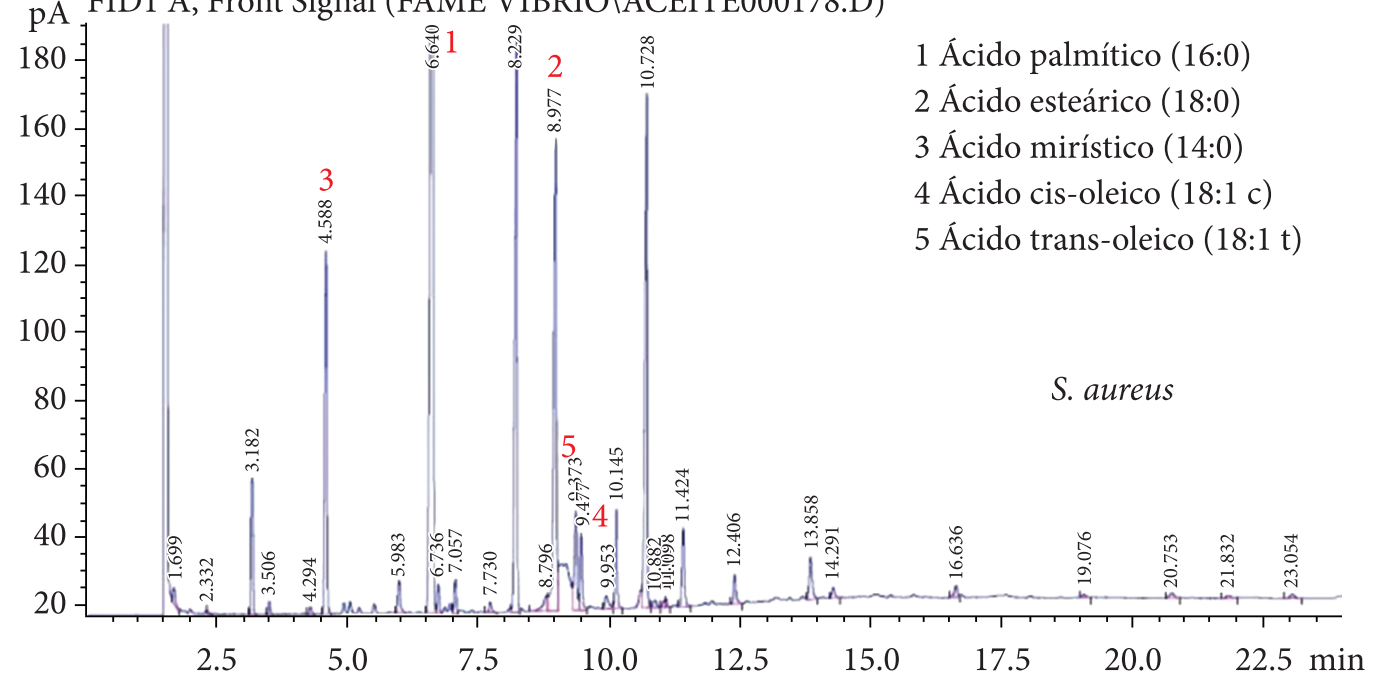

Figura 1 Continuación... 
Tabla 1 Perfil de ácidos grasos de cada muestra de bacterias analizada.

\begin{tabular}{|c|c|c|c|c|c|}
\hline Ac. graso & Bacterias & $\begin{array}{c}\% \text { en peso } \pm \text { desv. } \\
\text { estándar }\end{array}$ & $\begin{array}{l}\text { Ancho } \\
\text { del pico } \\
\text { (minutos) }\end{array}$ & $\begin{array}{c}\text { Tiempo } \\
\text { deretención } \\
\text { (minutos) }\end{array}$ & $\begin{array}{l}\mathrm{N}^{\circ} \text { de } \\
\text { platos } \\
\text { teóricos }\end{array}$ \\
\hline \multirow{6}{*}{$\begin{array}{c}\text { Ácido láurico } \\
(12: 0)\end{array}$} & V. cholerae & $5,04 \pm 0,270$ & 0,0293 & 3,209 & 191.922 \\
\hline & V. parahaemolyticus & $6,47 \pm 0,765$ & 0,0304 & 3,203 & 177.618 \\
\hline & V. vulnificus & $2,76 \pm 0,705$ & 0,0294 & 3,176 & 186.718 \\
\hline & V. alginolyticus & $2,67 \pm 1,118$ & 0,0249 & 3,181 & 261.125 \\
\hline & E. coli & $6,83 \pm 0,836$ & 0,0295 & 3,212 & 189.682 \\
\hline & S. aureus & $2,78 \pm 0,0351$ & 0,0265 & 3,182 & 230.689 \\
\hline \multirow{6}{*}{$\begin{array}{c}\text { Ácido mirístico } \\
(14: 0)\end{array}$} & V. cholerae & $4,50 \pm 0,236$ & 0,0364 & 4,6 & 255.524 \\
\hline & V. parahaemolyticus & $4,00 \pm 0,369$ & 0,0353 & 4,6 & 271.687 \\
\hline & V.vulnificus & $2,41 \pm 0,0153$ & 0,0477 & 4,589 & 148.087 \\
\hline & V. alginolyticus & $2,67 \pm 0,136$ & 0,0477 & 4,583 & 147.701 \\
\hline & E. coli & $5,85 \pm 0,747$ & 0,0322 & 4,614 & 324.126 \\
\hline & S. aureus & $7,45 \pm 0,485$ & 0,0455 & 4,595 & 163.180 \\
\hline \multirow{6}{*}{$\begin{array}{c}\text { Ácido palmítico } \\
(16: 0)\end{array}$} & V. cholerae & $22,81 \pm 1,348$ & 0,0393 & 6,609 & 454.487 \\
\hline & V. parahaemolyticus & $21,23 \pm 1,762$ & 0,0418 & 6,589 & 398.650 \\
\hline & V. vulnificus & $10,70 \pm 0,1744$ & 0,0408 & 6,575 & 415.519 \\
\hline & V. alginolyticus & $13,56 \pm 0,3044$ & 0,0447 & 6,573 & 345.965 \\
\hline & E. coli & $34,68 \pm 2,510$ & 0,0434 & 6,614 & 371.594 \\
\hline & S. aureus & $32,89 \pm 1,960$ & 0,0514 & 6,634 & 266.529 \\
\hline \multirow{6}{*}{$\begin{array}{c}\text { Ácido esteárico } \\
(18: 0)\end{array}$} & V. cholerae & $18,30 \pm 0,481$ & 0,0452 & 8,967 & 629.705 \\
\hline & V. parahaemolyticus & $15,38 \pm 0,408$ & 0,0493 & 8,942 & 526.375 \\
\hline & V. vulnificus & $18,12 \pm 6,050$ & 0,0442 & 8,947 & 655.587 \\
\hline & V. alginolyticus & $13,21 \pm 0,0624$ & 0,0557 & 8,936 & 411.809 \\
\hline & E. coli & $12,98 \pm 1,274$ & 0,0452 & 8,969 & 629.986 \\
\hline & S. aureus. & $9,86 \pm 0,0458$ & 0,0483 & 8,971 & 551.960 \\
\hline \multirow{5}{*}{$\begin{array}{c}\text { Ácido trans-oleico } \\
(18: 1 \mathrm{t})\end{array}$} & V. cholerae & $3,55 \pm 0,114$ & 0,0418 & 9,376 & 805.012 \\
\hline & V. parahaemolyticus & $5,00 \pm 0,962$ & 0,048 & 9,361 & 608.530 \\
\hline & V. alginolyticus & $1,54 \pm 0,121$ & 0,0383 & 9,358 & 955.187 \\
\hline & E.coli & $2,59 \pm 0,369$ & 0,0449 & 9,384 & 698.881 \\
\hline & S. aureus & $2,66 \pm 0,0917$ & 0,0529 & 9,369 & 501.874 \\
\hline \multirow{3}{*}{$\begin{array}{l}\text { Ácido cis-oleico } \\
(18: 1 \mathrm{c})\end{array}$} & V. cholerae & $5,07 \pm 0,816$ & 0,0451 & 9,374 & 691.221 \\
\hline & E.coli & $2,53 \pm 0,0800$ & 0,0422 & 9,493 & 809.659 \\
\hline & V. alginolyticus & $0,73 \pm 0,011$ & 0,0407 & 9,457 & 863.849 \\
\hline \multirow{6}{*}{$\begin{array}{c}\text { Ácido cis-linoleico } \\
(18: 2 \mathrm{c})\end{array}$} & V. cholerae & $3,52 \pm 0,206$ & 0,0422 & 10,149 & 925.425 \\
\hline & V. parahaemolyticus & $5,27 \pm 0,0854$ & 0,0453 & 10,138 & 801.361 \\
\hline & V. vulnificus & $9,68 \pm 0,245$ & 0,044 & 10,173 & 855.289 \\
\hline & V. alginolyticus & $2,64 \pm 0,150$ & 0,0426 & 10,128 & 926.520 \\
\hline & E. coli & $3,02 \pm 0,439$ & 0,0422 & 10,155 & 926.520 \\
\hline & S. aureus & $1,85 \pm 0,136$ & 0,0441 & 10,145 & 846.734 \\
\hline
\end{tabular}

$\mathrm{n}=3$ replicados. 
Tabla 1 Continuación...

\begin{tabular}{cccccc}
\hline Ac. graso & Bacterias & $\begin{array}{c}\text { \% en peso } \pm \text { desv. } \\
\text { estándar }\end{array}$ & $\begin{array}{c}\text { Ancho } \\
\text { del pico } \\
\text { (minutos) }\end{array}$ & $\begin{array}{c}\text { Tiempo } \\
\text { deretención } \\
\text { (minutos) }\end{array}$ & $\begin{array}{c}\mathrm{N}^{\circ} \text { de } \\
\text { platos } \\
\text { teóricos }\end{array}$ \\
\hline $\begin{array}{c}\text { Ácido araquídico } \\
(20: 0)\end{array}$ & V. cholerae & $8,74 \pm 0,136$ & 0,0482 & 11,438 & 901.003 \\
& V. parahaemoyticus & $2,66 \pm 0,130$ & 0,0496 & 11,41 & 850.121 \\
& V. vulnificus & $6,45 \pm 0,179$ & 0,0469 & 11,417 & 948.153 \\
& V. alginolyticus & $5,42 \pm 0,331$ & 0,0464 & 11,408 & 967.170 \\
& E. coli & $2,14 \pm 0,070$ & 0,051 & 11,439 & 804.926 \\
& S. aureus & $1,79 \pm 0,0751$ & 0,0516 & 11,424 & 784.254 \\
\hline
\end{tabular}

$\mathrm{n}=3$ replicados.

Tabla 2 Relación \% en peso entre ácidos grasos $\omega-9 / \omega-6$.

\begin{tabular}{lccccc}
\hline \multicolumn{1}{c}{ Ac. graso } & V. cholerae & V. parahaemolyticus & V. alginolyticus & E. coli & S. aureus \\
\hline$\omega-9(18: 1 \dagger+18: 1 \mathrm{c})$ & 8,62 & 5,00 & 2,27 & 5,12 & 2,66 \\
$\omega-6(18: 2 \dagger+18: 2 \mathrm{c})$ & 3,52 & 5,27 & 2,64 & 3,02 & 1,85 \\
Relación $\omega-9 / \omega-6$ & 2,4 & 0,95 & 0,86 & 1,70 & 1,44 \\
\hline
\end{tabular}

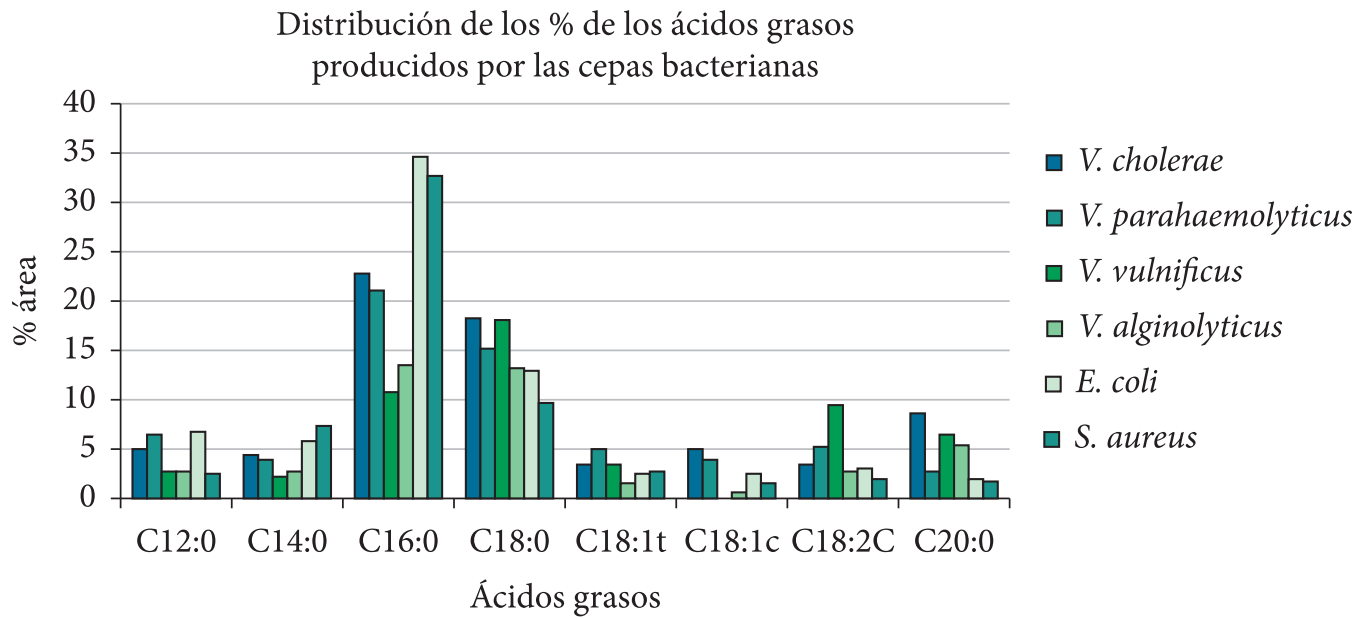

Figura 2 Distribución de los \% de los ácidos grasos producidos por las distintas cepas bacterianas.

tificación hay que tomar en consideración los otros ácidos presentes. Al analizar, finalmente, el $V$. alginolyticus con $V$. vulnificus, el primero comparte los ácidos palmítico, esteárico, araquídico y láurico pero se aprecia notoriamente la identificación ya que el porcentaje del ácido esteárico para $V$. alginolyticus es $13,21 \%$ mientras que para V. vulnificus, es $18,12 \%$, además el contenido del ácido palmítico para el primero es $13,56 \%$, y para el segundo es un $10,70 \%$.
Siguiendo con el análisis de la Tabla 1, se puede diferenciar Vibrio de E. coli debido a que el contenido del ácido mirístico es mayor para este último (5,85\%), ocurre lo mismo al diferenciar S. aureus de Vibrio. E. coli y S. aureus se separan e identifican de acuerdo al contenido del ácido mirístico $(7,45 \%$ para $S$. aureus) porque, además del porcentaje, las desviaciones estándar de ambos promedios de ellos en ambos son pequeños así como también con el contenido 
de los demás ácidos mayoritarios restantes: en E. coli el mayoritario es el cis-linoleico con 3,02\%, mientras que en $S$. aureus es el trans-oleico con $2,66 \%$.

La nomenclatura $\omega$ puede establecer una relación del nivel de insaturación, en el cual $\omega-9$ representa la suma de los ácidos monoinsaturados, $\omega$-6 representa la suma de los ácidos grasos diinsaturados, y $\omega-3$ representa a la suma de los ácidos grasos poliinsaturados. La relación entre este tipo de ácidos grasos proporciona una orientación para determinar el origen de los lípidos presentes en una determinada matriz. Se postula que, dado que el perfil de ácidos grasos es diferente entre las cepas ensayadas, también sea distinto la relación indicada. La Tabla 2 muestra una diferenciación, y por lo tanto un aporte para la identificación de cada especie de acuerdo a su relación $\omega-9 / \omega-6$ ya que indica una variación significativa de 2,4 para $V$. cholerae, 0,95 para $V$. parahaemolyticus, 0,86 para $V$. alginolyticus, 1,70 para E. coli, y un 1,44 para S. aureus respectivamente.

En conclusión se logró desarrollar una técnica complementaria para la identificación microbiológica, donde se observan diferencias en el perfil de ácidos grasos que permiten diferenciar a distintas especies dentro del género así como también con otros microorganismos como E. coli y $S$. aureus, que resulta ser rápida y de bajo costo relativo teniendo la implementación adecuada, presentándose como una alternativa a los métodos microbiológicos clásicos y métodos modernos basados en la caracterización por PCR.

\section{Referencias}

1 Brenner DJ, Krieg NR, Stanley, JT. Bergey's Manual of Systematic Bacteriology. 2nd ed. Springer; 2005.
2 Comisión de Vigilancia en Salud y Subcomisión de Vigilancia Epidemiológica. Mercosur XXX SGT $n^{\circ} 11$ "Salud". Acta no 01/08. 2008. Available from: http:// www.mercosur.int/msweb/SM/Noticias/Actas\%20 Estructura/Index_Atas_Est_GMC_SGT11.htm

3 Downes FP, Ito K. Compendium of Methods for the Microbiological Examination of Foods. 4th ed. APHA; 2001. http://dx.doi.org/10.2105/9780875531755

4 Doyle MP, Beuchatt LR, Montville, TJ. Microbiología de los Alimentos: Fundamentos y Fronteras. 2. ed. Zaragoza: Acribia; 2001.

5 Edward KD. The Fatty Acids of Euglena gracilis. Journal of Lipid Research 1964; 5(3):352-362.

6 Hilditch TP. The Chemical Constitution of Natural Fats. John Wiley and Sons, Inc.; 1956.

7 Lambert MA, Hickman-Brenner FW, Farmer III JJ, Moss CW. Differentiation of Vibrionaceae Species by Their Cellular Fatty Acid Composition. International Journal of Systematic Bacteriology 1983; 33:777-792. http://dx.doi.org/10.1099/00207713-33-4-777

8 Madigan MT, Martinko JM, Parker J. Brock Biología de los Microorganismos. 10th ed. Madrid: Pearson Prentice Hall; 2004.

9 Morrison RT, Boyd RN. Química Orgánica. 5. ed. México: Addison Wesley Longman de México S.A. de C.V.; 1998.

10 O'Leary WM. The Fatty Acids Of Bacteria. Bacteriological Reviews 1962; 26(4):421-447. PMid:16350179. PMCid:441163.

11 Zerbini E, Cardoso MM, Sequeira MD, Santi MN, Taher H, Larpin D et al. Utilidad de la Cromatografía Gaseosa para la identificación de Micobacterias. Medicina Buenos Aires; 1999. PMCid:85149.

12 Organización Panamericana de la Salud - OPS. Año epidemiológico [online]. OPS/OMS; 2002. [cited July 2009]. Available from: http://www.col.ops-oms. org/sivigila/anioepidemiologicodef.asp

13 Costa Rica. Reglamento Técnico Centroamericano De Los Alimentos RTCA 67.04.50:08. La Gaceta Digital Diario Oficial, La Uruca, 22 set. 2009. [online]. [cited July 2012]. Available from: http://www.reglatec.go.cr/ descargas/RTCAcriteriosmicrobiologicosSV02-08. pdf.

14 Vibrio [online]. 2008. p. 88-96. [cited June 2012] . Available from: http://www.scribd.com/doc/6655776/ Vibrio?__cache_revision $=1233900667$ \&__user_ id=-1\&enable_docview_caching $=1$ 